\title{
An Additional Look at Orientation Programs Nationally
}

\author{
Cassandra B. Whyte
}

Most colleges and universities have some type of orientation programming for new students, but designing the appropriate orientation model to meet the needs of incoming students is still an overwhelming task. Fortunately, research is available about how to determine needs of specific student populations before preparing educational programs.

There are certain general requirements which the literature indicates continue to appear as high priorities of college freshmen. These needs tend to focus on adjusting to academic work, financial information, and correlation of career and educational plans. The highest rated needs, however, generally remain academic in nature such as course availability and registration information (Moore, Higginson, \& White, 1981).

A 70-item questionnaire at the University Park Campus of Pennsylvania State University titled "Freshman Testing and Advising Progress Survey" (FTCAP) was designed to rank or prioritize new student needs. Authors of that instrument recommended that freshmen in most colleges and universities be assessed each year prior to college attendance to determine the major emphasis for that year's orientation programming (Moore, Higginson, \& White, 1981). Before this project, most orientation planners attempted to use the retrospective views of upperclassmen about past orientation experiences when planning programs. (Higginson, Moore, \& White, 1981).

Most students are overloaded with information during orientation programs and the stressful transition period for new students must be recognized when planning information for students (Klosterman \& Merseal, 1978; Knott \& Daher, 1978). Thus, the assessment of needs, search for information, and careful planning can help in the preparation of effective orientation materials.

The National Orientation Directors Association provides a very useful "Data Bank" for orientation directors to utilize regarding national trends and new ideas about acclimating students (NODA, 1982). There are still some types of additional information needed, however, regarding alternative registration techniques, evaluation methods, and program models which spurred the creation of this survey.

Cassandra B. Whyte was the Director of Support Services and the Counseling Center at West Virginia State College in Institute, West Virginia, at the time this article was originally published (Spring/ Summer, 1986) in the NODA Journal. 


\section{Method}

In an attempt to gather additional data, a survey was sent in 1983-84 to 750 randomly selected 4-year colleges and universities in the United States with 487 institutional representatives responding. Of the colleges responding, $62 \%$ had student populations under $4,000,25 \%$ of the institutions had student populations between 4,000 and 13,000 , and $13 \%$ had student populations over 13,000. This breakdown of respondent population was representative of the sample. Peterson's Guide to Undergraduate Study was utilized with a random numbers table to facilitate the selection process.

A 22-item questionnaire was developed which would have some items aimed at deciphering trends. Other questions provided information about program design, personnel, fees, program emphasis, projected outlook for orientation efforts in the future, and evaluation of orientation programs.

The following are sample questions:

1. Does your college offer Orientation Programs for new students? Yes No

8. Do you have mail-in registration? Yes No

9. Do you have a telephone registration? Yes No

14. Do you have additional or special orientation programs for:

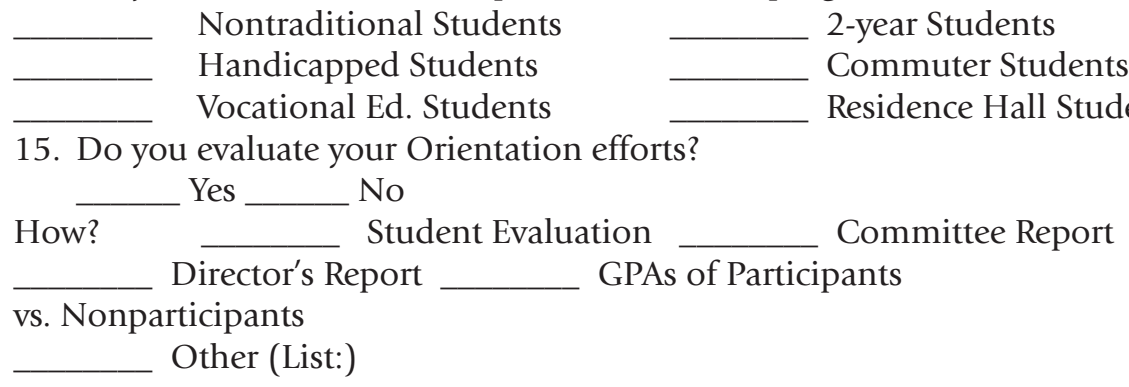

The response came in so well that it was not necessary to send follow-up letters.

\section{Results}

The table titled "Percentage of Responding Colleges/Universities With:" provides an overview of the specialization occurring within generic orientation programs nationally. More specifically, however, the following information was gleaned: 


\section{Program Design}

Ninety-nine percent of the college and/or university respondents indicated that they offered orientation programs for students. However, the respondents differed as to whom the orientation was targeted. Almost all institutions oriented full-time students, and $76 \%$ oriented full-time and part-time students. As a point of interest, $39 \%$ of the respondents targeted nontraditional students and provided additional or different information, 13\% targeted the handicapped, 28\% geared special sections of orientation toward the academically underprepared, $45 \%$ viewed residence hall students as a special group, and 30\% targeted commuter students as having special information needs within the framework of general activities. Also, 10\% targeted 2-year students, and 2\% targeted transfers during regular orientation activities. Of course, schools aimed special program efforts at several unique groups resulting in percentage overlap.

The most popular time frame for orienting new students seemed to be the traditional "Beginning of Semester Orientation," but Summer Orientation, as well as year-round program efforts, were additional features mentioned.

Information about alternative registration techniques was perhaps the most noteworthy. A large number (40\%), had the capacity for a mail-in registration. Many qualifiers, of course, were supplied by the respondents indicating restrictions on this type of registration process, limiting it to "adult learners," pre-registration periods, summer registration, and part-time student registration.

The survey also indicated that $15 \%$ of the educational institutions responding were experimenting with telephone registration processes. Again, however, the "yes" answers were qualified by indications that the phone-in registration was for "adult learners" only or "summer school students" only. Another study might focus on more specific information about methods used to efficiently conduct such alternative registrations and more precise definitions.

\section{Orientation Personnel}

This survey correlated well with the National Orientation Data Bank (1982) information indicating that, overwhelmingly, the task for orienting new students was the responsibility of student affairs personnel at various levels. Other units of colleges responsible for orientation were academic affairs, admissions, and counseling units. According to this survey, 22\% of the orientation advisers were paid an additional fee for extra work. The salaries ranged from extra money to free room and board and free T-shirts.

\section{Fees}

Fifty-five percent of respondents indicated that a special orientation fee was collected to defray costs of orientation program efforts. Those fees ranged from 
$\$ 3.50$ to $\$ 125$, and the higher fee range appeared to cover residential meal charges, testing, and credit hour charges where students received academic or institutional credit for completion of orientation.

Most schools varied program formats to include large group activities, small group activities, small group exercises, testing, counseling, and advising. Consequently, the popular vehicle for getting information to students appeared established as a combination of the above approaches. Various other activities during orientation consisted largely of activities for special groups needing additional or different information. It would appear that the attempts to refine traditional orientation delivery modes were geared more toward including those additional activities for special populations, rather than any revolutionary format changes. As previous research has indicated, institution specific data collection and needs assessment can be crucial to program success (Moore, Higginson, \& White, 1981; Higginson, Moore, \& White, 1981).

No great revelations regarding titles of traditional programs were gathered, but the most popular name was "Student Orientation," followed by "New Student Orientation." Some clever titles were "A Royal Beginning," "Individualized Educational Planning," "Welcome to our NeighborHOOD (Hood College)," "INCEPT-Orientation for the Urban Student," "Welcome Week," and "TSD-Total Student Development." Of course, additional orientation models, such as camping trips and city visits, surfaced in the 1970s.

\section{Program Emphasis}

Academic advising information seemed to be the most universal aspect of orientation programs, followed by campus information, testing information, and public relations information. Since student attrition has been noted as heaviest during the freshman year, the importance of academic advising seemed appropriate (Rootman, 1974; Marsh, 1966; Sagaria, Higginson, \& White, 1980).

\section{Future of Traditional Orientation Programs}

A large percentage of respondents, 71\%, thought that, although "phone-in" and "mail-in" registration had arrived at some colleges, traditional orientation/ information programs would continue to evolve. The reasons cited included the need for personal contact with students and thoughts that orientation programs were a necessary introduction to college. While alternative methods would expedite registration of returning students, transition needs could not be met by phone or mail.

In addition, this research deciphered a trend toward specialized information targeted at identified populations. This approach attempted to "customize" the orientation process and may become more common. 


\section{Evaluation Methods}

The most popular method of orientation evaluation was a "student evaluation" followed by a "committee report" method. Other methods included asking parents to evaluate the orientation efforts and seeking the opinions of faculty members. It was not clear, however, whether only faculty members and parents involved in orientation were asked for opinions.

Research studies investigating the grade point averages of participants versus non-participants were conducted by $3 \%$ of the respondents, but many of the respondents indicated a plan to start comparing grade point averages in the future. Thirty-one percent of the orientation directors prepared evaluation reports as a standard part of their work.

Although the numbers were very small, other methods mentioned included peer adviser evaluation, opinions of all personnel who worked with orientation, and a 5-year evaluation to provide perspective on effectiveness. An extremely large amount, $97 \%$, of the respondents, indicated they thought orientation programs were worthwhile.

\section{Student Management Information}

Interestingly, $84 \%$ of the respondents said that at their college or university upperclassmen returned to school after new students arrived. The need to segregate first-time students was apparently viewed as a necessary aspect of orientation programming.

\section{Discussion}

Although institutional orientation models have been similar for many years, this contribution to the literature provides additional data to consider when devising programs to help students adjust to college. Induction into the college community and conveyance of expectations and survival information have already helped many individuals to perform in the academic communities for years.

Refinement of programs is a continual challenge, and, after this survey and review of the literature, it appears that orientation directors are continuing to present generalized information to students with the additional aspect of targeting special population groups. Such special need groups as residence hall students, nontraditional students, handicapped students, academically underprepared students, commuter students, two-year students, and transfer students require specialized information.

In addition, mail-in registration and phone-in registration are gaining more acceptability to ease the drudgery of registration for staff and students by meeting the needs of a varied population. More information regarding successes and failures with alternative orientation techniques will be forthcoming as 
orientation directors continue to adapt and refine models. As program directors continue to customize orientation services, perhaps students will enter colleges better prepared to study and stay. Future studies may indicate the need for even more comprehensive orientation efforts to satisfy the more sophisticated consumers.

\section{References}

Haviland, M., \& Shaw, D. (1981). Factors related to college attrition. Colorado Journal of Educational Research, 20, 11-14.

Higginson, L., Moore, L., \& White, E. (1981). A new role for orientation: Getting down to academics. NASPA Journal, 19, 21-28.

Klosterman, L., \& Merseal, J. (1978). Another view of orientation. Journal of College Student Personnel, 19, 286-287.

Knott, J., \& Daher, D. (1978). A structured group program for new students. Journal of College Student Personnel, 15, 81-87.

Moore, L., Higginson, L., \& White, E. (1981). The priority of freshmen needs prior to college attendance. The College Student Journal, 15, 81-87.

Rootman, I. (1972). Voluntary withdrawal from a total adult socializing organization: A model. Sociology of Education, 45, 158-270.

Sagaria, M., Higginson, L., \& White, E. (1980). Perceived needs of entering freshmen: The primacy issues. Journal of College Student Personnel, 21, 243-247. University of Maryland Orientation Office. (1982). NODA Data Bank. National Orientation Directors Association.

\section{TABITE}

\section{Percentage of Responding College/Universities With:}

Orientation Programs

$99 \%$

Mail-in Registration

$40 \%$

Phone-in Registration

$15 \%$

Orientation Fees

$55 \%$

Upperclassmen Returning After New Students

$84 \%$

Research Evaluations of Orientation Efforts

$3 \%$

Special Target Orientation for:

1. Residence Hall Students

$45 \%$

2. Nontraditional Students

$39 \%$

3. Academically Underprepared Students

$28 \%$

4. Commuter Students

$30 \%$

5. Handicapped Students

$13 \%$

6. Two-Year Students

$10 \%$

7. Transfer Students

$2 \%$

The above table represents 487 responses from a randomly selected group of 750 colleges and universities in 1983-84. 